\title{
Thoughts on the Problems in the Application of Cloud Accounting Practice
}

\author{
Xu Qunying \\ Xi'an Peihua University, Xian City, Shaanxi Province Changan District, Peihua South Road, Xi'an \\ 710125, China
}

Keywords: cloud accounting; accounting practice; application; problem; countermeasure

\begin{abstract}
At present, information technology has been widely used in various industries, and it has also been applied in the accounting industry. In the future, cloud computing technology will be widely used in the accounting industry, which is of great significance to improve the efficiency and quality of accounting staff and promote the development of accounting information. However, with the widespread application of cloud accounting in accounting practice, it can be found that cloud accounting has certain deficiencies. Based on the overview of cloud accounting development, this paper analyzes the problems existing in the application of cloud accounting in accounting practice and proposes corresponding countermeasures.
\end{abstract}

\section{Introduction}

Cloud accounting work needs to rely on Internet technology to provide accounting services (such as accounting management, accounting services, accounting, etc.) for companies and individuals. It is precisely because of the application of computer technology in accounting practice that cloud accounting system can effectively reduce the cost of enterprises and improve the efficiency and quality of accounting work. However, cloud accounting has some problems in the application of accounting practice, which is not good for the development and application of cloud accounting.

\section{Overview of cloud accounting development}

\subsection{Cloud accounting meaning}

Cloud accounting is an accounting model developed by cloud computing technology. Enterprises can use the cloud accounting model for accounting work. Compared with traditional accounting methods, they are faster and more accurate, and can be analyzed, processed and ontrolled corporate economic activities in time, which is of great significance to improving the economic efficiency of enterprises.

\subsection{Accounting Advantages}

The main role of cloud computing is to improve the efficiency of accounting work, enhance the emphasis on business management, reduce the cost of enterprises, and improve the competitiveness 
of enterprises.

\subsubsection{Low investment}

With the cloud computing service model, enterprises only need to provide corresponding terminals and networks and can obtain computing support, stable software feedback, and highaccuracy accounting services. The expenses that enterprises need to bear are the accounting services and network fees purchased by cloud accounting service providers, and these services can also adopt the installment payment method, which can effectively reduce the pressure on corporate funds.

\subsubsection{Service is more professional}

The cloud accounting service provider provides more professional hardware management services for enterprises, and its cloud computing equipment is larger in scale. The server and data storage center are more scientifically set up, and various backup power sources are more abundant, security measures such as anti-static and anti-wave rushing are adopted. And the company is equipped with a professional equipment maintenance team, which can effectively ensure the stable and safe operation of the accounting information system.

\subsubsection{Data processing is faster}

The traditional accounting software data processing capability will be affected by the performance of the equipment. Many staff members are dissatisfied with the performance of the computer. In order to effectively solve this problem, it is necessary to update the computer equipment in time, which will increase the cost of the enterprise. The data processing speed in the cloud accounting mode is faster, which can effectively solve this problem.

\subsubsection{Strong synergy control}

From the internal perspective of the enterprise, after adopting the cloud accounting model, the accounting workers have a deeper understanding of the business process, and they can rationally allocate various resources owned by the enterprise through effective cooperation with the information flow coordination department, effectively improve the business operation efficiency and economic benefits; from the external perspective of the enterprise, the cooperative enterprise can share the accounting information of the relevant business, so as to obtain effective information, help the enterprise to understand the supply and demand of upstream and downstream enterprises, and at the same time, the enterprise can file tax returns at any time. Accounts and audits, etc., can enhance the effectiveness of business operations by strengthening internal and external collaborative control.

\section{Analysis of problems in cloud accounting application in accounting practice}

\subsection{Cloud accounting service enterprise income, cost and expenses cannot reflect the actual situation of the business}

In the past, accounting personnel can rationally allocate corporate income and expenses based on their own work experience, the company's future cost and cost changes, so that the actual economic situation of the enterprise can be fully reflected. However, when adopting the cloud accounting method, it is necessary to use a computer for calculation and matching. Throughout the calculation process, the Internet cloud only proportions its income and expenses according to time, and does not fully reflect the relationship between the company's income and cost. From this point of view, 
although cloud accounting can timely match the enterprise's revenue cost, it cannot fully demonstrate the company's expectations for the future, nor can it predict the possible operational risks of the enterprise. It can be seen that how to effectively solve the ratio of enterprise income and cost is an important issue that cloud accounting firms need to solve.

\subsection{Accounting documents are difficult to obtain and accept}

The accounting documents will effectively record the occurrence or completion of the business of the enterprise, which is classified as a grade book. The enterprise shall fill in and review the accounting documents in accordance with relevant regulations, and shall be registered in the books after the audit to reflect the actual economic business of the enterprise. In the past, in the accounting work, if an enterprise had an economic business, it would form multiple accounting documents. For example, after the enterprise purchases the goods, the financial department must follow the purchase order of the purchasing department. The original certificate such as the inspection report of the inspection department and the invoice of the supplier shall be used for the payment of the payment. Although this accounting work requires multiple procedures, the responsibility of each department is relatively clear, which can effectively improve the accuracy of accounting business. However, in the cloud accounting model, the accounting work of the enterprise is carried out in the cloud of the Internet, and no paper documents are required. Similarly to the purchase of goods, the finance department only needs to pay according to the payment reminder of the cloud computing system. In this way, it will affect the authenticity of the entire business economic business. In addition, the economic responsibilities of various departments are not clear. With the continuous development of technology, it will be difficult to obtain legal and effective paper accounting documents. At the same time, these electronic accounting documents may have fraud problems.

\subsection{Problems in book management}

Accounting books are important information and files for accounting work. In the past, in the accounting work, the accounting books were regularly reviewed and kept by a special person. However, in the cloud accounting work, enterprises store accounting books in the form of data information in the Internet accounting service system, and do not adopt paper file management. If the enterprise accounting service system is attacked by hackers, attacked by an opponent, or the system fails, the financial information of the enterprise may be lost. If the company does not back up the enterprise accounting books in other computers, it will improve the difficulty of economic business review and proofreading. In addition, with the widespread use of cloud accounting mobile terminal devices, each employee of the enterprise can report accounts through the network, so that enterprise accounting information can be updated in real time (the enterprise needs to authorize each employee, and it can obtain part of the accounting book by authorization) ). If an employee mishandles or a retired employee steals corporate financial information, it will affect the company's development. The study found that one of the main reasons why many companies do not adopt cloud computing is to worry about the loss of data information.

\subsection{Accounting Information Security Issues}

With the emergence and application of cloud accounting, it can effectively reduce the accounting work cost of enterprises and improve the efficiency and modernization level of enterprise accounting work, but it will also increase the hidden dangers of accounting information security. Since cloud accounting relies on Internet technology, it may be subject to various attacks during the networking process, and financial information stored in cloud devices may be lost or tampered with. 
The financial information of the enterprise belongs to the trade secret of each enterprise. If it is acquired by the rival company, it will pose a serious threat to the enterprise. In addition, accounting information may be stolen or tampered by hackers, which shows that the security of accounting information stored in cloud devices may face greater threats. At the same time, if the company does not strengthen the internal control work, there will be problems such as insufficient confidentiality of accounting personnel, inaccurate privilege positioning, and lack of clear division of responsibilities. These issues will affect the accounting information security of enterprises.

\subsection{Problems faced by accounting review}

Cloud computing will have an impact on the audit of corporate economic operations. In the past accounting work, auditors were required to use the verification method, review method, and comparison method to review accounting information. However, in the cloud computing environment, since the entire accounting work needs to be based on computers, and the accounting information will be distributed in different network nodes, the audit trails are not clear enough, which will increase the difficulty of the enterprise accounting auditors. In addition, unlike the traditional review, the auditor in the cloud accounting mode needs to obtain the necessary information from the cloud accounting service provider. However, the information provided by the cloud accounting service provider cannot be guaranteed to be complete and accurate. Online transactions are characterized by virtuality and openness. Therefore, some transaction records cannot obtain valid accounting documents, which will increase the difficulty of accounting workers. At the same time, in the cloud accounting model, auditors not only need to master the auditing standards and auditing principles, but also need to master the cloud computing application knowledge.

\section{Corresponding countermeasures}

\subsection{In-depth study of the theory applied by cloud accounting in accounting practice}

With the formation and application of cloud computing technology, cloud services have also been widely used in enterprise management. China's cloud accounting service providers are also increasing, such as Kingdee and UF, whose technology and service level are also constantly improving. However, China's research on cloud accounting theory is not deep enough, and it has not formed a complete theoretical system. Cloud accounting is an inevitable trend of accounting development. Therefore, in order to promote the stable and rapid development of cloud accounting, it is necessary to deeply study the theoretical knowledge of cloud accounting, thus forming a complete cloud accounting system. In addition, with the continuous development of cloud computing, traditional accounting standards and norms can no longer meet the needs of accounting work. Therefore, when promoting cloud accounting in China, it is necessary to formulate corresponding laws and standards to strengthen the supervision of cloud accounting service providers.

\subsection{Improve the corresponding laws and regulations}

In order to promote the stable development of cloud accounting, government departments need to rationally adjust the corresponding norms and guidelines based on their actual development. The US government has enacted laws and regulations such as the Federal Information Resource Management Law and the National Information Infrastructure Protection Act. This is of great significance to the promotion of the quality of cloud accounting information security supervision. 
Cloud accounting service enterprises belong to emerging enterprises. The technical level of each enterprise is different, and the credit level of enterprises is different. Therefore, China not only needs to improve cloud accounting standards and standards, but also needs to strengthen the management and audit of cloud accounting service enterprises based on the advanced experience of other countries, and establish and improve the laws and regulations related to cloud computing and cloud accounting, so as to the accounting industry is developing steadily.

\subsection{Improve the overall quality of employees}

After the enterprise uses the cloud accounting model, the enterprise accounting workflow and working standards are different from the original accounting work. How to quickly complete the accounting work and strengthen the connection between the businesses is an issue that the accounting staff needs to study in depth. Whether accounting workers can quickly grasp the cloud computing model and its comprehensive quality level affects the important factors of cloud accounting promotion. In the cloud accounting model, accountants no longer simply use manual calculations, but use computer or mobile terminal equipment for accounting calculations. Therefore, accounting workers need to master the knowledge of computer use, and at the same time need to master the knowledge of Internet cloud computing, so that the cloud accounting model can be effectively promoted. In recent years, information technology and business have developed at a faster rate. Therefore, enterprises are faced with a variety of economic businesses. Accounting workers need to have corresponding business capabilities and practical capabilities to ensure that they can handle them correctly when they encounter different economic businesses. Accounting workers not only need to learn independently, but government departments and enterprises need to regularly organize accounting workers to learn professional accounting knowledge, change their accounting work methods and concepts, and help accounting workers to correctly establish the working concept centered on the needs of corporate financial accounting work. Improve the overall quality of accounting workers. As the level of informatization of accounting work continues to increase, accounting workers need to switch to online financial analysis and management to promote the stable development of enterprises.

\subsection{Improve cloud accounting security}

Information security has always been an important issue for experts, scholars and enterprises, which is also an important factor affecting the development and promotion of cloud accounting. Therefore, after fully studying the cloud computing market, the Chinese government needs to scientifically formulate cloud computing standards and norms, formulate laws and regulations related to information security, and improve China's information security laws based on real-time changes in the cloud computing market. First of all, the purpose is to ensure the security of "cloud" accounting information, and to develop an information security risk assessment system. Government departments need to personally commission or entrust relevant organizations to evaluate the technical level and goodwill level of cloud accounting service providers, and the security of elimination is low. Secondly, enterprises need to establish cloud accounting infrastructure construction, and at the same time need to regularly maintain the accounting service system and timely develop new software, so as to effectively improve the security of accounting information.

\subsection{Strengthening internal control of enterprises}

In the process of cloud accounting development, more emphasis is placed on the construction 
and development of related hardware and business processes, and the quality of internal control work is not emphasized. The internal control problems that enterprises may have include: insecure API interfaces, illegal use of cloud computing resources, and sharing of technical vulnerabilities, which are also important factors affecting the speed of cloud accounting development. In order to strengthen internal control, enterprises need to start from the following aspects: First, enterprises need to scientifically formulate and implement account password management system, so as to ensure the security of cloud accounting data storage and data transmission, avoid competing companies and other personnel to steal or tamper with corporate accounting information; Secondly, clearly define the duties of accounting workers, so as to avoid the situation of shirking responsibility, to ensure that accounting workers can strictly follow the relevant norms for accounting work; finally, strengthen the control of accounting information input, output and storage.

\subsection{Sound audit method}

The enterprise auditor shall conduct a detailed assessment of the internal control safety of the enterprise according to the corresponding auditing standards and principles, and adopt the most appropriate auditing techniques and methods. If problems are found during the auditing process, timely corrections shall be made and preventive measures shall be formulated. It ensures that the accounting information system can operate stably and safely. With the development and promotion of the cloud accounting model, the accounting review work needs to be changed, and the accounting review method is continuously reformed, so as to ensure that the accounting review method meets the relevant work requirements. In addition, with the continuous development of cloud accounting, it is necessary to speed up the construction and improvement of the cloud audit platform. Today, as the level of informatization of accounting work continues to improve, it is necessary to use the Internet cloud model to review accounting information and fully study the risks of cloud computing services, so as to reduce the work cost of the accounting review department and improve its work efficiency. In short, using the Internet cloud mode to audit accounting information can effectively improve the efficiency and quality of accounting information management, and improve the informationization level of the accounting industry.

\section{Conclusion}

With the continuous development of technology, computer technology has been widely used in accounting work, thus forming a modern accounting form of cloud accounting. However, cloud accounting has some shortcomings in the application of accounting practice, which has a negative impact on accounting work. We need to take effective measures to deal with the problems existing in the application of cloud accounting in accounting practice, so as to promote the stable and sustainable development of cloud accounting.

\section{References}

[1] Wu Yuanyuan. Application of Cloud Accounting in Enterprise Financial Management [J]. Market Research, 2016(8): 60-61.

[2] Zhou Yufei, Luo Liping. Application and Construction of “Cloud Accounting” in Enterprise Accounting Informationization [J]. International Business Accounting, 2017(10): 57-58.

[3] Wang Xinyue. Risk analysis and prevention research of cloud accounting [D]. 2016.

[4] Chen Peiru. The Application of Cloud Accounting in Enterprise Accounting Informationization[J]. Modern Economic Information, 2016(19):223.

[5] Chen Xia. Discussion on the Application of Cloud Accounting in Accounting Informationization of Small and Medium Enterprises [J]. China Management Information, 2017, 20(11): 37-38.

[6] Shi Leifen. Application of Cloud Accounting in Accounting Informationization of Small and Medium Enterprises [J].

Modern Economic Information, 2017(18): 256. 